\title{
Nachhaltigkeit erfordert Bewusstsein und gemeinsames Handeln
}

D ie Union Internationale Contre le Cancer (UICC) hat in einer Weltkrebsdeklaration dazu aufgerufen, in allen Ländern effektive Krebskontrollprogramme zu implementieren. Sie hat für die kommende Dekade Ziele gesetzt, die so selbstverständlich klingen, dass man zur Tagesordnung übergehen möchte - und doch sind wir in Deutschland um einiges, weltweit dramatisch weit von einer Realisierung entfernt.

Für uns und andere wohlhabende Länder sind die Gründe wenig schmeichelhaft: Umweltverschmutzung, Genussgifte, zu reichliche und fehlerhafte Ernährung sowie der Mangel an Bewegung sind die Hauptursachen von Krebs - unserem mangelhaften Bewusstsein für eine gesunde Lebensführung geschuldet. Hinzu kommt, dass nicht nur die Primärprävention, die Vorsorge unbefriedigenden ist, auch die Bereitschaft zur Sekundärprävention, der Früherkennung ist ungenügend.

Würden wir uns dieser Problematik bewusst, würden wir uns motivieren, würden wir persönlich entsprechend handeln, dann ließen sich die Inzidenzen der führenden „Killerkrebse“ um wenigstens ein Drittel reduzieren, Krankheitsverlauf und Lebenserwartung Krebskranker signifikant verbessern. Aber vor lauter Bäumen, vor lauter Konjunktiven sehen wir den Wald nicht mehr.

Was können nun wir Onkologen selbst und was in und mit unseren wissenschaftlichen Organisationen tun, um die sich durch Lebensführung und demografischen Wandel bedrohlich abzeichnende Krebsepidemie einzudämmen? Was ist zu tun, damit auch in Zukunft die wachsenden Kosten bei schwindenden Ressourcen solidarisch getragen werden können?

Rationierung und Priorisierung zulasten der Alten, Kranken und Schwachen darf nicht die Antwort sein. Die Ökonomisierung ärztlicher Arbeit führt zur Ökonomisierung ärztlicher Ethik und zur Verbiegung unserer moralischen Grundwerte. Einfach so weiterzuwurschteln, dem gesundheitspolitischen Flickenteppich weitere Flicken anzuhäkeln reicht nicht mehr aus.

Eine nachhaltige Lösung lässt sich nur gemeinsam mit allen Beteiligten und dem mündigen Bürger realisieren. Dabei sind große Anstrengungen zur Lebensführung ,von klein auf“ mit einer neuen

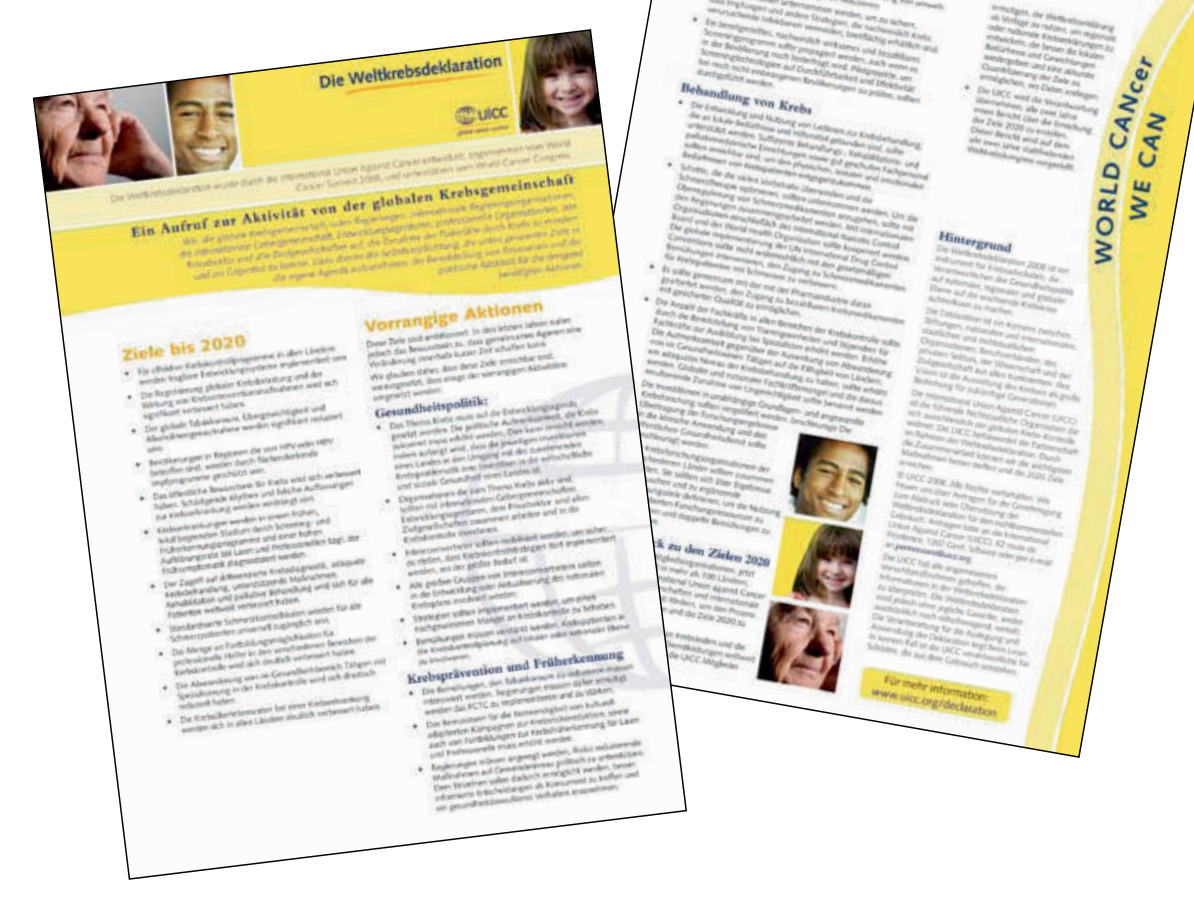

Bescheidenheit beim Griff in den Solidartopf zu verbinden.

Um weltweit im Kampf gegen den Krebs voranzukommen, hat die UICC Ziele und vorrangige Aktionen formuliert, die zum Erfolg führen können:

„Wir, die globale Krebsgemeinschaft, rufen Regierungen, internationale Regierungsorganisationen, die internationale Gebergemeinschaft, Entwicklungsagenturen, professionelle Organisationen, den Privatsektor und alle Zivilgesellschaften auf, die Zunahme der Todesfälle durch Krebs zu mindern und ins Gegenteil zu kehren. Dazu dienen die Selbstverpflichtung, die Ziele in die eigene Agenda aufzunehmen, die Bereitstellung von Ressourcen und der politische Rückhalt für die dringend benötigten Aktionen."

Packen wir's doch an! Es gibt ja schon viele Erfolg versprechende Aktionen, bei denen wir mitmachen können und die es zu bündeln gilt.

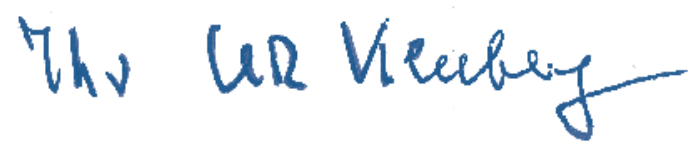

Mehr Informationen unter www.uicc.org/ved

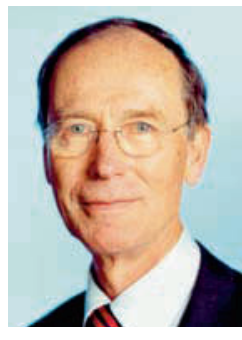

Prof. Dr. med. Ulrich R. Kleeberg Hämatologischonkologische Praxis Altona, Hamburg E-Mail: urkleeberg@ hopa-hamburg.de 